\title{
PENGETAHUAN PERAWAT TENTANG SPIRITUAL CARE DI SALAH SATU RUMAH SAKIT SWASTA KATOLIK DI KOTA BANJARMASIN
}

\author{
Bernadeta Peta Pili ${ }^{1}$, Anastasia Maratning ${ }^{2}$, Bernadeta Trihandini ${ }^{3}$ \\ 1,2,3 Sekolah Tinggi Ilmu Kesehatan Suaka Insan Banjarmasin \\ Email:bernadeta@gmail.com
}

\begin{abstract}
Behavior that is based on knowledge will be more lasting than behavior that is not based on knowledge. Nurses are professional health workers who have the ability to take actions that are intellectual, interpersonal, moral, responsible and authoritative, and treat patients by looking at them holistically who have bio-psycho-social-spiritual needs. Spiritual Care are practices and procedures performed by nurses on patients to fulfill their spiritual needs. Given the large role of the spiritual aspect of care for individual health, the provision of spiritual services is an important thing that needs to be performed by nurses. This study aimed to find description of nurses' knowledge about spiritual care at a Catholic private hospital in Banjarmasin. This research was descriptive-quantitative research with survey data collection. The research sample was taken using a consecutive sampling technique with a total of 50 nurses. The results of the study were analyzed using descriptive statistics using a frequency distribution table. This study shows that the majority of nurses' knowledge about spiritual care was in the good category (48\%), sufficient (38\%), and less (14\%). The results showed that nurses' knowledge about spiritual care in hospitals was in the good category.
\end{abstract}

Keywords: Knowledge, Nurses, Spiritual Care

\begin{abstract}
ABSTRAK
Perilaku yang didasari oleh pengetahuan akan lebih langgeng daripada perilaku yang tidak didasari oleh pengetahuan. Perawat merupakan tenaga kesehatan professional yang memiliki kemampuan untuk melakukan tindakan yang bersifat intelektual, interpersonal, moral, bertanggung jawab dan berkewenangan serta merawat pasien dengan memandangnya secara holistik yang memiliki kebutuhan bio-psiko-sosial-spiritual. Spiritual Care adalah praktek dan prosedur yang dilakukan oleh perawat terhadap pasien untuk memenuhi kebutuhan spiritualnya. Mengingat besarnya peran aspek spiritual care bagi kesehatan individu, maka pemberian pelayanan spiritual merupakan hal yang penting yang perlu dilakukan oleh perawat. Penelitian ini bertujuan mengetahui bagaimana gambaran pengetahuan perawat tentang spiritual care, di salah satu rumah sakit swasta Katolik di Banjarmasin. Penelitian ini adalah penelitian deskriptifkuantitatif dengan pengumpulan data secara survey. Pengambilan sampel penelitian dilakukan dengan menggunakan tehnik consecutive sampling jumlah 50 perawat. Hasil penelitian dianalisa dengan menggunakan statistik deskriptif dengan menggunakan tabel distribusi frekuensi. Penelitian ini menunjukkan bahwa mayoritas pengetahuan perawat tentang spiritual care berada pada kategori baik (48\%), cukup (38\%), dan kurang (14\%). Hasil penelitian menunjukkan bahwa pengetahuan perawat tentang spiritual care di rumah sakit berada dalam kategori baik.
\end{abstract}

Kata Kunci: Pengetahuan, Perawat, Spiritual Care 


\section{PENDAHULUAN}

Perawat merupakan tenaga kesehatan professional yang memiliki kemampuan untuk melakukan tindakan yang bersifat intelektual, interpersonal, moral, bertanggung jawab dan berkewenangan melaksanakan asuhan keperawatan (Departemen Kesehatan Republik Indonesia / DEPKES RI, 2012).

Perawat juga memiliki kesempatan yang paling besar untuk memberikan asuhan keperawatan yang komprehensif dengan membantu klien untuk memenuhi kebutuhan dasar yang holistik yaitu bio, psiko, sosiokultural dan spiritual (Hamid, 2008).

Penjelasan dari McCormick dalam tulisannya menjelaskan bahwa $77 \%$ pasien yang berkunjung ke rumah sakit di United States (US) menginginkan untuk membicarakan keluhan spiritual mereka sebagai bagian dari pelayanan kesehatan.

Hasil penelitian yang telah dilakukan oleh beberapa peneliti di berbagai rumah sakit di Indonesia, diketahui berbagai hal penting mengenai angka kejadian kecemasan yang tidak dilakukan pelayanan spiritual. Penelitian yang dilakukan oleh Hodge et al (2011) tentang kebutuhan spiritual pasien, mengungkapkan bahwa kebutuhan spiritual mereka adalah kebutuhan akan makna, tujuan dan harapan dalam hidup, hubungannya dengan Tuhan, praktek spiritual, kewajiban agama, hubungan dengan sesama dan hubungan dengan perawat.

Koeniq (2007) menemukan efek dari terpenuhinya spiritual care pasien yaitu $90 \%$ dapat menurunkan tekanan darah pada pasien hipertensi dan $75 \%$ pasien akan berumur panjang. Jenkins (2010) juga mengatakan bahwa melalui intervensi spiritual care, pasien akan merasa damai dan sejahtera pada saat pasien mengalami stres dan sedih, pasien juga merasakan akan lebih mudah memahami makna dan tujuan hidupnya pada saat masa-masa sulit dalam hidupnya.

Memperhatikan besarnya aspek spiritual care bagi kesehatan maka pemberian pelayanan spiritual merupakan hal yang penting yang perlu dilakukan oleh perawat, namun dalam prakteknya kadang kurang disadari. Menurut perawat hal ini disebabkan beberapa alasan yaitu kurangnya perhatian perawat terhadap spiritualnya sendiri, adanya kendala waktu, kurangnya pengetahuan terkait spiritual care, kurang jelasnya perbedaan antara agama dan spiritualitas, terkadang pasien beda kepercayaan dengan perawat, dan kurangnya bimbingan dari manajer perawat (Amankaa et al, 2009).

Hasil wawancara dengan unit keperawatan yaitu kepala ruangan dan perawat pelaksana, pasien dewasa dengan kesadaran penuh, mereka mengatakan bahwa sebenarnya perawat sudah melaksanakan atau mengaplikasikan tentang spiritual care namun perawat belum menyadari bahwa tindakan caring adalah bagian dari spiritual care karena pemahaman mereka tentang spiritual care itu hanya dilakukan oleh pemuka agama.

Data temuan yang dikemukakan diatas menunjukkan pentingnya mengetahui lebih dalam mengenai pengetahuan perawat tentang spiritual care di rumah sakit, teutama di rumah sakit swasta katolik di Banjarmasin-Kalimantan Selatan.

\section{METODELOGI}

Penelitian ini merupakan penelitian kuantitatif dengan menggunakan rancangan penelitian deskriptif. Variabel dalam penenilitian ini adalah variabel tunggal yaitu pengetahuan perawat tentang spiritual care. Populasi dalam penelitian ini adalah semua perawat yang bekerja di salah satu rumah sakit swasta Katolik di kota Banjarmasin-Kalimantan Selatan, yaitu sebanyak 132 orang. Sampel dalam penelitian ini yaitu perawat yang memenuhi kriteria inklusi dan eksklusi berjumlah 50 orang yang, diambil dengan menggunakan rumus slovin. Teknik sampling yang digunakan yaitu consecutive sampling.

Penelitian ini dilaksanakan di rumah sakit swasta Katolik di Kota Banjarmasin-Kalimantan Selatan. Waktu Penelitian dilakukan pada tanggal 12 Maret 2019 sampai 6 April 2019. Pengumpulan data menggunakan kuesioner.

Uji validitas dan reliabilitas dilakukan pada 30 responden di salah satu rumah sakit swasta Katolik di Banjarmasin. Analisis validitas menggunakan rumus pearson product moment, dan analisis reliabilitas menggunakan program komputer dengan rumus cronbach alpha. Analisis univariat dibuat dalam bentuk tabel distribusi frekuensi dan narasi berdasarkan masing masing kategori variabel.

\section{HASIL DAN PEMBAHASAN}

\section{Analisa Univariat}

\section{Pengetahuan Perawat tentang Spiritual Care di Rumah Sakit Swasta Katolik di Kota Banjarmasin.}

Tabel 1.1 Distribusi Frekuensi Pengetahuan Perawat tentang Spiritual Care di Rumah Sakit Swasta Katolik di Kota Banjarmasin.

\begin{tabular}{clcc}
\hline $\mathbf{N}$ & Pengetahuan & F & $\mathbf{( \% )}$ \\
$\mathbf{o}$ & & & \\
\hline 1. & Baik & 24 & 48 \\
2. & Cukup & 23 & 46 \\
3. & Kurang & 3 & 6 \\
\hline & Total & $\mathbf{5 0}$ & $\mathbf{1 0 0}$ \\
\hline
\end{tabular}

Sumber: Data primer 2019

Tabel 1.1. menunjukkan bahwa sebagian besar pengetahuan perawat tentang spiritual care adalah berada dalam kategori baik, yaitu sebanyak 24 orang 
(48\%). Sedangkan perawat yang memiliki pengetahuan dengan kategori cukup adalah sebanyak 23 orang (46\%), dan perawat yang memiliki pengetahuan dengan kategori kurang adalah sebanyak 3 orang $(6 \%)$.

Responden yang masuk dalam kategori baik artinya hal ini, dikarenakan responden banyak mendapat informasi dan wawasan pengetahuan dilihat dari usia 31-40 tahun untuk kognitifnya, pemikiran sudah matang ataupun memecahkan masalahnya sudah baik. Selain usia perawat yang sudah matang, pengetahuan yang baik ini juga di pengaruhi oleh ratarata pendidikan terakhir perawat adalah Sarjana Keperawatan dan profesi ners. Pendidikan juga mempengaruhi pengetahuan karena hal ini menunjukan bahwa perawat sudah banyak belajar selain teori yang diperoleh secara akademik juga dapat belajar dari pengalaman dan situasi tempat kerjanya.

Notoatmodjo (2010) pengetahuan merupakan hasil dari tahu, dan ini terjadi setelah seseorang melakukan penginderaan terhadap suatu objek. Pengetahuan pada umumnya didapat dari pengalaman, juga dapat diperoleh dari buku, media massa dan elektronik. Pengetahuan atau kognitif merupakan domain yang sangat penting untuk terbentuknya tindakan seseorang ovent behavior. Pernyataan ini pun didukung oleh penelitian dari Maryam S.R, dkk (2007), dalam Rahmadani S (2016) yang menyatakan bahwa perawat adalah profesi yang sifat pekerjaannya 29 berada dalam situasi yang menyangkut hubungaı aııа manusia, terjadi proses interaksi yang saling mempengaruhi dan dapat memberikan dampak terhadap tiap-tiap individu yang bersangkutan.

Walaupun pada umumnya pengetahuan perawat di rumah sakit sudah baik, namun masih ada perawat yang pengetahuanya tentang spiritual care dalam kategori cukup sebanyak 23 responden (46\%) dan kurang 3 responden $(6 \%)$. Hal ini menunjukan bahwa tidak semua perawat mengetahui dan melaksanakan spiritual care. Oleh karena itu, penting bagi Rumah Sakit untuk memberikan pengetahuan dan pelatihan agar perawat yang ada di Rumah Sakit Swasta Katolik di Kota Banjarmasin dapat memahami dan melaksanakan spiritual care dengan baik.

\section{Pengetahuan Perawat Berdasarkan Indikator Spiritual Care di Rumah Sakit Swasta Katolik di Kota Banjarmasin.}

Tabel 1.2 Distribusi Frekuensi Pengetahuan Perawat tentang Dasar-Dasar Spiritual Care di Rumah Sakit Swasta Katolik di Kota Banjarmasin.

\begin{tabular}{llcc}
\hline No & Pengetahuan & F & $\mathbf{( \% )}$ \\
\hline 1. & Baik & 34 & 68 \\
2. & Cukup & 12 & 24 \\
3. & Kurang & 4 & 8 \\
\hline & Total & $\mathbf{5 0}$ & $\mathbf{1 0 0}$ \\
\hline
\end{tabular}

Sumber: Data primer 2019.

Tabel 1.2 menunjukkan bahwa responden penelitian yang sebagian besar memiliki pengetahuan tentang dasar-dasar spiritual care adalah mereka yang memiliki kategori baik, yaitu sebanyak 34 orang (68\%). Sedangkan perawat yang memiliki pengetahuan dengan kategori cukup adalah sebanyak 12 orang (24\%), dan perawat yang memiliki pengetahuan dengan kategori kurang adalah sebanyak 4 orang $(8 \%)$.

Hasil pengetahuan perawat tentang dasar-dasar sudah baik ini di dukung dengan jawaban tertinggi pada item pertanyaan salah satu dasar keperawatan adalah aspek perawatan yang integral dan fundamental dimana perawat menunjukkan kepedulian kepada pasien untuk meningkatkan dalam memberikan asuhan keperawatan dan diikuti item pertanyaan praktek dan prosedur yang dilakukan oleh perawat terhadap pasien untuk memenuhi kebutuhan spiritual pasien.

Notoadmojo (2010) menunjukkan bahwa secara umum, pengetahuan seseorang dipengaruhi oleh pengalaman hidup (pengetahuan sejati), tingkat pendidikan (semakin tinggi pendidikan seseorang semakin tinggi pula pengetahuannya), kesehatan fisik, terutama kesehatan panca indra, usia (berhubungan dengan daya tangkap dan ingatan terhadap suatu materi) dan media massa/buku (sumber informasi). Pernyataan ini didukung oleh penelitian Chan (2013), Mc Sherry \& Jamieson (2013) yang mengatakan bahwa spiritual care merupakan aspek perawatan yaitu memiliki nilai-nilai cinta dan kasih sayang serta kebaikan hati, memiliki sikap yang hangat, memiliki sikap caring, mendengarkan dan salah satu fungsi dasar dari menejemen yang merupakan proses untuk mencapai tujuan aspek perawatan yang integral dan fundamental dimana perawat menunjukkan kepedulian kepada pasien.

Hasil penelitian yang didukung oleh teori penelitian menyimpulkan, pengetahuan perawat sudah baik dengan pengembangan perawat, penting untuk dilaksanakan dan memudahkan perawat dalam menjalankan tugasnya agar tujuan yang di tetapkan mendapatkan hasil yang baik. 
Tabel 1.3 Distribusi Frekuensi Pengetahuan Perawat tentang Tujuan Spiritual Care di Rumah Sakit Swasta Katolik di Kota Banjarmasin.

\begin{tabular}{clcc}
\hline No & Pengetahuan & F & $\mathbf{( \% )}$ \\
\hline 1. & Baik & 25 & 50 \\
\hline 2. & Cukup & 18 & 36 \\
\hline 3. & Kurang & 7 & 14 \\
\hline & Total & $\mathbf{5 0}$ & $\mathbf{1 0 0}$ \\
\hline
\end{tabular}

Sumber: Data primer 2019

Tabel 1.3 menunjukkan bahwa sebagian besar pengetahuan perawat tentang tujuan spiritual care di Rumah Sakit Swasta Katolik di Kota Banjarmasin adalah dengan kategori baik, yaitu sebanyak 25 orang (50\%). Sedangkan perawat yang memiliki pengetahuan dengan kategori cukup adalah sebanyak 18 orang (36\%) dan perawat yang memiliki pengetahuan dengan kategori kurang adalah sebanyak 7 orang (14\%).

Responden yang masuk dalam kategori baik artinya menunjukkan pada umumnya pengetahuan perawat tentang tujuan sudah baik, dibuktikan dengan jawaban responden terbanyak pada pertanyaan untuk mencapai tujuan pelayanan asuhan keperawatan secara efektif dan efisien. Tujuan pelayanan ini dipahami sebagai upaya untuk memenuhi kebutuhan akan makna, tujuan, dan harapan yang erat kaitannya dengan kebutuhan akan hubungan dengan Tuhan, dan untuk memberi kenyamanan kepada pasien.

Notoadmojo (2010) menyatakan bahwa sikap menggambarkan suka atau tidak suka seseorang terhadap suatu tujuan pelayanan, yang sering diperoleh dari pengalaman sendiri atau melalui orang lain. Pernyataan ini didukung oleh penelitian Saharuddin, Safrullah Amir dan Rosmina (2018) yang mengatakan bahwa sebagai sumber daya yang ada didalam diri manusia yang mendorong untuk menemukan arti, nilainilai dan makna hidup, dan ketika dalam kondisi tidak nyaman, spiritual care diharapkan tetap menjadi sumber daya yang mendorong manusia menaruh harapan dan kepercayaan pada kekuatan yang lebih tinggi agar tetap dapat melihat arti, nilai-nilai dan makna dari peristiwa kehidupan.

Hasil penelitian tujuan spritual care selain memiliki pengetahuan yang baik, masih ada perawat yang berpengetahuan dalam kategori cukup sebanyak 18 responden (36\%), kurang sebanyak 7 responden (14\%). Hal ini menunjukkan walaupun pada umumnya pengetahuan perawat di rumah sakit sudah dalam kategori baik, tapi masih ada perawat yang berpengetahuan cukup dan kurang. Hal ini dibuktikan dengan jawaban terendah yang dijawab oleh responden yaitu menjelaskan tujuan spiritual care secara efektif dan efisien mendukung terapi dan perawatan pasien untuk kesembuhan pasien. Sebagai tambahan, masih ada perawat yang tidak menjelaskan tujuan spiritual care sebagai sistem pelayanan yang baik dan efisien kepada pasien.
Tabel 1.4 Distribusi Frekuensi Pengetahuan Perawat tentang Manfaat Spiritual Care di Rumah Sakit Swasta Katolik di Kota Banjarmasin.

\begin{tabular}{llcc}
\hline No & Pengetahuan & F & $\mathbf{( \% )}$ \\
\hline 1. & Baik & 25 & 50 \\
\hline 2. & Cukup & 20 & 40 \\
\hline 3. & Kurang & 5 & 10 \\
\hline & Total & $\mathbf{5 0}$ & $\mathbf{1 0 0}$
\end{tabular}

\section{Sumber: Data Primer 2019}

Tabel 1.4 menunjukkan sebagian besar pengetahuan perawat tentang manfaat spiritual care di rumah sakit adalah berada dalam kategori baik, yaitu sebanyak 25 orang $(50 \%)$. Sedangkan perawat yang memiliki pengetahuan dengan kategori cukup adalah sebanyak 20 orang $(40 \%)$, dan perawat yang memiliki pengetahuan dengan kategori kurang adalah sebanyak 5 orang $(10 \%)$.

Responden yang masuk dalam kategori baik menunjukkan telah memahami tentang manfaat spiritual care. Dalam penelitian ini yaitu sebanyak 25 responden $(50 \%)$ yang menunjukkan bahwa pengetahuan mereka akan manfaat spiritual care sudah baik.

Notoatmodjo (2010) menyatakan bahwa pengetahuan atau ranah kognitif merupakan domain yang sangat penting dalam membentuk tindakan seseorang. Semakin tinggi pendidikan seseorang, semakin mudah pula mereka menerima informasi, dan pada akhirnya pengetahuan yang dimilikinya akan semakin banyak. Sebaliknya, jika seseorang memiliki tingkat pendidikan yang rendah, maka akan menghambat perkembangan sikap orang tersebut terhadap penerimaan informasi dan nilai-nilai yang baru diperkenalkan. Pengetahuan dapat diperoleh melalui proses belajar yang didapat dari pendidikan. Pernyataan ini didukung oleh penelitian Suhaemi (2004) dan (Maryam S. R, dkk, 2007, dalam Rahmadani S, 2016), yang mengatakan bahwa fungsi perawat adalah profesi yang sifat pekerjaannya selalu berada dalam situasi yang menyangkut hubungan antar manusia. Hubungan tersebut terjadi sebagai sebuah proses yang saling mempengaruhi dan dapat memberikan dampak terhadap tiap-tiap individu yang bersangkutan.

Hasil tersebut dibuktikan dengan jawaban tertinggi pada item pernyataan membantu individu mencapai keseimbangan yang diperlukan untuk memelihara kesehatan dan kesejahteraan, serta untuk beradaptasi dengan penyakit dan item pertanyaan menuntun kebiasaan hidup sehari-hari, sebagai sumber dukungan serta sumber kekuatan dan penyembuhan dalam situasi ketidakpastian dan kecemasan memiliki integritas, 
harapan, dan rasa damai serta memberikan solusi akan keluhan maupun perasaan yang di utarakan oleh pasien.

Hasil dari penelitian yang didukung oleh teori peneliti menyimpulkan bahwa pengetahuan perawat tentang manfaat spiritual care sudah baik. Hal ini menunjukan bahwa spiritual care sebagai ukuran kenyamanan. Spiritual care mempengaruhi kesehatan dan kesejahteraan hidup pada individu. Spiritual care juga berperan sebagai sumber dukungan dan kekuatan bagi individu.

Tabel 1.5 Distribusi Frekuensi Pengetahuan Perawat tentang Langkah-Langkah Spiritual Care di Rumah Sakit Swasta Katolik di Kota Banjarmasin.

\begin{tabular}{llcc}
\hline No & Pengetahuan & F & $\mathbf{( \% )}$ \\
\hline 1. & Baik & 24 & 48 \\
\hline 2. & Cukup & 19 & 38 \\
\hline 3. & Kurang & 7 & 14 \\
\hline & Total & $\mathbf{5 0}$ & $\mathbf{1 0 0}$
\end{tabular}

Sumber: Data Primer 2019

Tabel 1.5 menunjukkan bahwa sebagian besar pengetahuan perawat tentang langkah-langkah spiritual care di rumah sakit berada dalam kategori baik, yaitu sebanyak 24 orang (48\%). Sedangkan perawat yang memiliki pengetahuan dengan kategori cukup adalah sebanyak 19 orang (38\%), dan perawat yang memiliki pengetahuan dengan kategori kurang adalah sebanyak 7 orang $(14 \%)$.

Responden yang masuk dalam kategori baik artinya sebagian besar responden telah memahami tentang langkah-langkah spiritual care. Hal ini dibuktikan dengan jawaban tertinggi yang ditunjukkan oleh responden pada item pertanyaan yang menunjukkan kemampuan untuk mendengarkan dengan aktif keluhan dan harapan, serta secara aktif berbicara kepada pasien atau keluarga tentang masalahnya, memberikan privacy dan suasana yang tenang untuk kebutuhan berdoa dan merujuk pada pemuka agama bila diperlukan.

Notoatmojo (2010) menunjukkan bahwa pengetahuan atau kognitif merupakan domain yang sangat penting dalam langkah-langkah membentuk sikap dan tindakan seseorang. Jika pengetahuan baik maka diharapkan pula sikap dan perilakunya juga baik. Pendapat ini pun sejalan dengan pendapat dari Butcher (2013), Giddens (2015) dan (Handini,2017) yang menunjukkan bahwa ada beberapa langkah- langkah spiritual care yang dapat dilakukan oleh perawat, diantaranya adalah membangun rasa percaya dengan pasien atau keluarga melalui komunikasi terapeutik, memperkenalkan diri dan menjelaskan tujuan, menunjukkan belarasa dan menerima pasien serta peka terhadap kebutuhan pasien, menghormati nilai-nilai dan keyakinan pasien atau keluarga, mendengarkan dengan aktif terhadap keluhan, harapan, dan berbicara kepada pasien atau keluarga (memfasilitasi pasien atau keluarga untuk merefleksikan harapannya), menjawab pertanyaan pasien dan keluarga, memberikan privacy dan suasana yang tenang untuk kebutuhan berdoa, menghadirkan diri dengan sepenuh hati, sesuai budaya untuk memberi rasa nyaman, kontak mata, memperlihatkan bahasa tubuh ekspresi wajah yang sesuai dengan situasi pasien atau keluarga, memfasilitasi untuk kebutuhan berdoa, merujuk pada pemuka agama bila diperlukan.

Penelitian ini menunjukkan bahwa perawat yang bekerja di rumah sakit sudah memahami pentingnya langkah-langkah spiritual care dalam pemberian asuhan keperawatan yang baik. Langkahlangkah spiritual care ini nantinya menjadi hal yang patut untuk diterapkan dalam memberikan asuhan keperawatan spiritual care menjadi langkah yang baik untuk proses perawatan atau tindakan keperawatan dalam memberikan asuhan keperawatan untuk mendukung kesembuhan pasien yang membutuhkan perawatan sampai memperoleh kesembuhan.

Hasil penelitian ini menunjukkan bahwa pengetahuan perawat tentang spiritual care adalah baik. Hal ini menunjukkan bahwa perawat dapat memberi makna bahwa pengetahuan atau kognitif merupakan domain yang sangat penting dalam membentuk sikap dan tindakan seseorang. Jika pengetahuan baik maka diharapkan pula sikap dan perilakunya juga baik, artinya semakin tinggi tingkat pengetahuan perawat terhadap spiritual care maka semakin tinggi pula sikap perawat terhadap spiritual care. Dalam penelitian ini pengetahuan yang dimaksud adalah pengetahuan perawat terhadap spritual care.

\section{KESIMPULAN}

Penelitian ini menyimpulkan bahwa pada umumnya pengetahuan Perawat sudah baik dengan nilai presentase $48 \%$. Pengetahuan tersebut terbagi menjadi pengetahuan akan dasar-dasar Spiritual Care, kategori baik (68\%). Tujuan Spiritual Care, kategori baik sebanyak (50\%). Manfaat Spiritual Care, kategori baik (50\%), dan langkah-langkah Spiritual Care, kategori baik $(48 \%)$. Penelitian selanjutkan sangat diharapkan dapat dilakukan, terutama untuk menilai variablevariabel lain yang berpengaruh terhadap asuhan keperawatan spiritual.

\section{Ankowledgement}

Terimakasih kepada pimpinan Rumah Sakit Suaka Insan Banjarmasin beserta jajarannya, serta Stikes Suaka Insan Banjarmasin. 


\section{Daftar Pustaka}

Amankwaa.L,Jenkins.M, Trent.B,Wikoff.K, (2009) The positive effect of spirituality of health, well being, and life satisfaction. Nursing Center Journal Issue, 40,29-36.

Butcher H.K, Bulechek G.M, Dochterman J.M.M, Wagner C. (2013) Nursing Interventions Classification (NIC) Elsevier Health Sciences.

Chan C.S dan Jean E.R (2013) Religious Coping, Posttraumatic Stress,Psychological Distress, and Posttraumatic Growth Among Female Survivors Four years After Hurricane Katrina. Journal of Traumatic Stress.

Departemen Kesehatan RI Pusat Pendidikan Tenaga Kesehatan (2012) Buku HIV/AIDS untuk SPK/AKPER, Jakarta.

Giddens J.F, (2015) Concepts for Nursing Practice,Elsevier Health Sciences.

Hamid, A.Y., 2008, Bunga Rampai Asuhan Keperawatan Kesehatan Jiwa, Jakarta, EGC.

Handini, Bernadeta. (2017), Pengaruh Caring : Pendekatan Spiritual Terhadap Kecemasan Pasien Dan Keluarga Pada Pasien Stroke Di RSUD Dr. H. Moch. Ansari Saleh. Banjarmasin.

Hodge, David, Horvath, Violet et al (2011), Spiritual needs in health care settings: a qualitative metasynthesis of Clients' Perspectives. SocialWork,56, 16-30

Jenkins,M.L (2010) The Nurse leader role in spiritual care for hospitalizedbpatients: A grounden theory approach. Journal of Clinical Nursing.

Koenig H.G, (2007) Spirituality in Patient Care. Second Edition.Philadelphia;Templeton Foundation Press.

McCormick. T.R (2014) Spirituality and Medicine. https://depts. washington.edu/bhdept/ethicsmedicine/bioethics.

McSherry, $\mathrm{W}$ \& Jamieson,S. (2013) The qualitative findings from on online survey investigating nurses'perceptions of spirituality and spiritual care. Journal of Clinical Nursing, 22(21-22), 3170-3182.

Hidayat, A. 2007. Riset keperawatan dan tehnik penulisan ilmiah. Jakarta: Salemba medika

Notoatmodjo, S. 2010. Metodologi Penelitian Kesehatan. Jakarta : Rineka Cipta.

Saharuddin1,SafrullahAmir2,Rosmina3,(2018),Penerapa $n$ Model Pelayanan Keperawatan Berbasis Spiritual Ditinjau Dari Aspek Proses Asuhan Keperawatan Spritual Di Rumah Sakit Islam
Faisal Makassar. Hospital Majapahit Vol 10 No. 1 Februari 2018. 